AJIE - Asian Journal of Innovation and Entrepreneurship

(e-ISSN: 2477-0574 ; p-ISSN: 2477-3824)

Vol. 01, No. 02, May 2016

\title{
INISIASI PENGEMBANGAN INKUBATOR BISNIS IT SEBAGAI JEMBATAN WIRAUSAHAWAN MUDA IT (Studi Kasus Di Fakultas MIPAUNS )
}

\author{
Sarngadi Palgunadi Yohanes ${ }^{1)}$, Mohtar Yunianto*2), Rudi Hartono ${ }^{3)}$ \\ 1) Riset Group Ilmu Rekayasa Komputasi, Universitas Sebelas Maret \\ 2) Riset Group Teori dan Komputasi, Universitas Sebelas Maret \\ 3) Riset Group Pervasif, Universitas Sebelas Maret \\ E-mail : mohtaryunianto@staff.uns.ac.id
}

\begin{abstract}
Faculty of Mathematics, University of March Surakarta has 2 study program in the field of information technology, namely Studies Program Informatics and Diploma Course 3 of Informatics, with the availability of human resources that are reliable in the field of IT both teaching staff and students as well as the opening of self-employment opportunities in the field of information technology, by Therefore do initiation weeks to form the Information Technology business incubation. Business incubator that was developed utilizing the resources available in the faculty that students, lecturers and the equipment available, initiation was done by the establishment of a start-up company called Warehouse Techno engaged in the services of IT services, service sertifiksi competence in IT result is students can implement science which have been obtained in the study by producing some IT products are used by the community as well as activities and JENI CISCO certification of competence.
\end{abstract}

Keywords: IT business incubators, start-up company, entrepreneurial

\begin{abstract}
ABSTRAK
Fakultas MIPA Universitas Sebelas Maret Surakarta memiliki 2 Program Studi di bidang teknologi informasi, yaitu Program Studi Informatika dan Program Studi Diploma 3 Teknik Informatika, dengan tersedianya sumber daya manusia yang handal dibidang IT baik staff pengajar maupun mahasiswanya serta terbukanya peluang wirausaha dibidang teknologi informasi, oleh karena itu dilakukan inisiasi utuk membentuk inkubasi bisnis Teknologi Informatika. Inkubasi bisnis yang dikembangkan memanfaatkan sumber daya yang tersedia di fakultas yaitu mahasiswa, dosen serta peralatan yang tersedia, inisiasi yang dilakukan berupa pembentukan start up company yang bernama Gudang Techno yang bergerak di jasa layanan IT, layanan sertifiksi kompetensi bidang TI hasilnya adalah mahasiswa dapat mengimplementasikan ilmu yang telah diperoleh dalam kuliah dengan menghasilkan beberapa produk IT yang dimanfaatkan oleh masyarakat serta kegiatan sertifikasi kompetensi CISCO dan JENI.
\end{abstract}

Kata kunci : inkubator bisnis IT, start up company, wirausaha

\section{PENDAHULUAN}

Era globalisasi ekonomi dan era informasi mendorong sektor industri menggunakan sumber daya manusia lulusan perguruan tinggi yang kompeten. Akan tetapi tidak semua lulusan perguruan tinggi dapat terserap kedalam lapangan kerja tersebut. Di sisi lain, krisis ekonomi menyebabkan jumlah lapangan kerja tidak tumbuh, dan bahkan berkurang karena bangkrut. Dalam kondisi seperti ini, maka lulusan perguruan tinggi dituntut untuk tidak hanya mampu berperan sebagai pencari kerja tetapi juga harus mampu berperan sebagai pencipta kerja. Oleh karena itu, agar supaya perguruan tinggi mampu memenuhi tuntutan tersebut, 
berbagai inovasi diperlukan diantaranya adalah inovasi pembelajaran.

Inkubator bisnis tersebut diasosiasikan sebagai salah satu inovasi dalam pembelajaran, yang ditujukan sebagai wadah transformasi pembentukan sumberdaya manusia kurang kreatif dan produktif menjadi sumberdaya manusia yang memiliki motivasi wirausaha secara kreatif, inovatif, produktif dan kooperatif dan merupakan langkah awal dari penciptaan wirausaha yang memiliki keunggulan kompetitif [1].

Perguruan Tinggi merupakan salah satu elemen penting partisipasinya dalam proses inkubasi, dikarenakan inkubator bisnis memiliki relevansi yang sangat penting sekali terhadap TriDharma Perguruan Tinggi [2]. Inkubator bisnis dapat berfungsi sebagai sarana praktik dari konsep-konsep bisnis akademik [3].

Teknologi informasi dan komunikasi merupakan sektor yang sangat signifikan perkembangannya dalam dunia usaha. Dikarenakan teknologi tersebut ditujukan untuk mempermudah pekerjaan manusia, yang kemudian diterapkan pada sektor industri yang digunakan untuk mempermudah kerja selain itu juga untuk meningkatkan efektifitas, efisiensi dan produktivitas perusahaan [4].

Tujuan yang hendak dicapai dalam kegiatan pengabdian ini adalah terbentuknya suatu startup company yang merupakan hasil kegiatan wirausaha dibidang IT antara staff Pengajar dan Mahasiswa sehingga mahasiswa memiliki motivasi dan pemahaman dalam bidang wirausaha baik di produk maupun layanan jasa.

\section{METODE PELAKSANAAN}

Khalayak Sasaran dalam kegiatan adalah Mahasiswa dan staff pengajar di Fakultas MIPA Universitas Sebelas Maret. Metode Kegiatan yang digunakan dalam kegiatan ini dilakukan dengan beberapa tahapan yaitu :

1. Inisiasi dan inventarisasi ketersediaan saran dan prasarana yang menunjang pembentukan wirausaha di bidang IT.

2. Pembentukan start-up company yang bergerak di bidang IT yang diberi nama Gudang Techno.
3. Pembuatan proposal penawaran kerjasama pengembangan aplikasi.

4. Pembuatan website inkubasi bisnis IT

5. Pelaksanaan kegiatan inkubasi bisnis IT

\section{HASIL DAN PEMBAHASAN}

Kegiatan yang dilaksanakan untuk membentuk inkubator bisnis Teknologi Informasi diantaranya adalah :

1. Pembentukan start-up company yang bergerak dibidang jasa layanan IT.

Telah dibentuk start-up company yang bergerak di bidang IT yang diberi nama Gudang Techno dan telah memiliki alamat web di http://gudangtechno.web.id, adapun usaha yang dilakukan adalah

A. Inkubator Bisnis Sebagai Pusat Inovasi menghasilkan produk software dan pekerja profesi IT

Memberikan pelayanan dalam hal membantu mengkomersialkan penemuanpenemuan ataupun inovasi-inovasi yang dihasilkan oleh mahasiswa tingkat akhir hasil berupa produk Tugas Akhir. Selain itu dapat berwujud pula sebagai pengembangan, restrukturisasi dan rekayasa produk serta penyediaan tenaga profesional dalam bidang IT.

Pengembangan aplikasi berupa System untuk Deteksi Bencana Banjir yang merupakan kerjasama dengan partnert baik kami baik peneliti pada sebuah universitas maupun maupun pakar dalam Pusat Studi Bencana di UNS Solo sehingga menciptakan fasilitas untuk meminitoring dan memberikan notifikasi mengenai ketinggian level sungai di daerah tertentu. Sistem yang dikembangkan menggunakan telemetri komunikasi dengan menggunakan fasilitas dari provider sehingga dapat menjangkau untuk daerah pedesaan maupun support untuk berbagai device. aplikasi real time monitoring ketinggian level air dapat di akses melalui alamat http://banjir.mitigasi.com

B. Inkubator Bisnis Sebagai Pusat
Konsultasi 
Program ini bertujuan membantu memecahkan masalah-masalah yang dihadapi oleh hasil binaan yang berhubungan dengan usaha / bisnis teknologi informasi. Sifat bantuannya adalah konsultasi yang dilakukan secara sinambungan dengan memegang prinsip manajemen kewirausahaan dalam bidang teknologi informasi.

C. Inkubator Bisnis Sebagi Pusat Pelatihan dan sertifikasi

Program pelatihan merupakan bagian dari layanan inkubator bisnis dalam untuk menambah wawasan serta pengetahuan tentang pengelolaan wirausaha baik bagi calon wirausaha maupun kepada wirausaha itu sendiri.

Pelatihan dan sertifikasi yang telah dilakukan diantaranya adalah :

a. Sertifikasi JAVA JENI

b. Sertifikasi CISCO

c. Pelatihan Multimedia

Yang dilakukan di Laboratorium Sertifikasi Fakultas MIPA UNS

\section{KESIMPULAN}

Berdasarkan keterangan-keterangan yang telah dipaparkan sebelumnya dan dari pelaksaan kegiatan dapat disimpulkan bahwa:

1. Inkubasi bisnis dapat dimulai dengan pendirian start company untuk memacu mahasiswa dan dosen untuk turut terlibat dalam kewirausahaan bidang IT, yaitu dalam bidang Jasa berupa Software development dan IT Jaringan serta dalam bidang Network dan Jaringan.

2. Kegiatan sertifikasi baik mahasiswa maupun dosen dapat memberikan pengetahuan lebih untuk dapat dimanfaatkan dalam kegiatan kegiatan yang menunjang kewirausahaan.

\section{DAFTAR PUSTAKA}

[1] Anderson, J,S,. Manz, C,C, \& Prussia, G,E. (1998). Self-leadership and performance outcomes: the mediating influence of self efficacy. Journal of Organizational Behavior, 19, 523-538.
[2] Sanusi, Achmad (1994). Menelaah Potensi Perguruan Tinggi Untuk Membina Program Kewirausahaan dan Mengantar Kehadiran Pewirausaha Muda. Makalah Seminar Kewirausahaan, Inkubator Bisnis Bandung,STMB -KADIN Jabar.

[3] Muller, Susan, (2008), Encouraging Future Entrepreneurs : The Effect of entrepreneurship Course Characteristic on Entrepreneur Intention, Disertation of University of University of St. Gallen Irchel, Zurich

[4] Sarosa, Pietra (2004). Kiat Praktis Membuka Usaha, Langkah Awal Menjadi Entrepreneur Sukses .Jakarta:Elex Media Komputindo 